\title{
Innovation modes in the Swiss service sector a cluster analysis based on firm-level data
}

\section{Report}

Author(s):

Hollenstein, Heinz

Publication date:

2001

Permanent link:

https://doi.org/10.3929/ethz-a-004296381

Rights / license:

In Copyright - Non-Commercial Use Permitted 


\title{
Innovation Modes in the Swiss Service Sector
}

\author{
A Cluster Analysis Based on Firm-level Data
}

\author{
Heinz Hollenstein * \\ Swiss Federal Institute of Technology, Institute for Business Cycle Research, \\ Weinbergstrasse 35, CH-8092 Zurich, Switzerland \\ E-mail: hollenstein@kof.gess.ethz.ch \\ Austrian Institute of Economic Research (WIFO) \\ P.O. Box 91, A-1103 Vienna, Austria \\ E-mail: hollenst@wifo.ac.at
}

\begin{abstract}
Despite the importance of the service sector, our knowledge of innovative activities in services is still rather poor. From this perspective, a first aim of this paper is to contribute to a better understanding of innovation patterns prevailing in this sector. To this end, firms which are similar in terms of a large set of innovation indicators have been grouped into clusters. For the Swiss service sector, we identified five clusters which clearly differ with respect to a large number of innovation-related factors (knowledge networks, appropriability, technological opportunities, market conditions, etc.) and some structural properties of firms (size, age, industry affiliation, export orientation). The clusters may thus be interpreted as specific „modes of innovation“. Secondly, we investigated whether the five innovation modes are „economically equivalent“, what would imply that unordered classifying of similar firms is more appropriate than (the frequently practised) ranking of industries according to their innovation intensity.

The empirical results are not clear-cut: Although the evidence supports the classification approach quite well, the ranking procedure cannot be refuted. This ambiguous result can be interpreted as follows: On the one hand, in accordance with the classificatory perspective, firms dispose of a certain degree of freedom in selecting an economically viable innovation strategy in similar economic and technological environments. On the other hand, the room of manoeuvre is restricted by structural characteristics closely related to the industry hierarchy in terms of innovation intensity, factor endowment, etc. (ranking perspective). Therefore, the general practice of ranking industries according to their innovation intensity, e.g. in order to assess their competitiveness, remains sensible. This conclusion holds true, however, only if the measurement of innovation intensity is based on a large set of indicators to take into account the within-industry diversity of innovation modes.
\end{abstract}

JEL codes: O31, O33

Key words: Innovative activity in services, Innovation patterns, Knowledge networks, Clusteroriented technology policy

* The research for the present study has been supported by the Swiss Ministry of Economic Affairs. The paper has been revised during a sabbatical spent at the Austrian Institute of Economic Research (WIFO), Vienna. 



\section{Introduction}

The innovation process is a complex phenomenon characterised by several stages reaching from basic research up to the penetration of the market with new products and the introduction of new production techniques within the firm. Therefore a whole series of indicators is needed to describe and measure a firm's innovative activities each of them stressing specific aspects but also exhibiting measurement errors. Using the information contained in such a system of indicators we developed in earlier work a composite measure of innovation intensity and used it for ranking firms and industries of the manufacturing as well as the service sector according to their innovativeness (Hollenstein, 1996; Arvanitis et al., 1998).

Implicitly, this ranking assumes that an industry is a (more or less) homogeneous entity with respect to the innovativeness of its firms, an assumption which contradicts a basic hypothesis of the evolutionary view of technological change. In the latter framework, one would rather look for groups of firms characterised by similar innovation patterns which are conceptualised as unordered categories (,innovation modes“). Such a purely classificatory procedure allows for the (presumed) heterogeneity of an industry with respect to the innovation strategies pursued by its firms. This approach allows for the co-existence of different innovation modes which - at least for a certain time period - may turn out as equivalent in terms of economic performance. Which of these innovation strategies are sustainable in the longer run is decided in the course of a market-driven selection process whose outcome is not predictable (see, for example, Metcalfe, 1995).

We explored this classificatory approach in an earlier study for the Swiss manufacturing sector using firm-level data (Arvanitis and Hollenstein, 1998). The analysis yielded five innovation modes which showed similarities to those identified by other authors (Pavitt, 1984; Cesaratto and Mangano, 1993; Arundel et al., 1995). The specificities of our classification could be explained to a large extent by some structural characteristics of the Swiss economy. In the present paper we look for innovation patterns in service industries of the Swiss economy by using quite the same methodology as in our study related to manufacturing which had been inspired by the work of Cesaratto and Mangano (1993).

Despite high and growing importance of the service sector empirical work related to services is still quite scarce in empirical economics in general and in innovation research in particular. ${ }^{1}$ This unsatisfactory situation is partly due to conceptual problems (,what makes service innovations different?" $),{ }^{2}$ partly to a lack of data. ${ }^{3}$ It is thus not surprising that, to our knowledge, there is only one

1 It is very revealing that the „Handbook of the Economics of Innovation and Technological Change“ edited by Stoneman (1995) does not treat the service sector at all. Metcalfe and Miles (Editors, 2000) may serve as a survey on many aspects of innovation in services. these matters.

3 Although the „Community Innovation Survey 1996“ (CIS II) and similar surveys conducted in non-EU countries such as Canada and Switzerland cover now also the service sector there are still rather few econometric investigations pertaining to this part of the economy. To mention are, for example, a study for the Netherlands (Brouwer und Kleinknecht, 1998), some work at the European Center for Economic Research (ZEW), Mannheim (e.g., Ebling und Janz, 1999), a few studies at Statistics Canada (e.g., Gellatly, 1999) as well as some analyses for Switzerland (Arvanitis et al., 1998; Donzé and Lenz, 1999; Arvanitis, 2000). 
study which is looking for innovation patterns in the service sector in a similar way as the present paper does (Evangelista, 2000). ${ }^{4}$ By applying cluster analysis to data for nineteen service industries in Italy this author succeeds to identify four ,patterns of innovation“ with two of them showing some similarities to innovation types in manufacturing identified by Pavitt (1984) and the other authors mentioned above.

The aim of the present paper is twofold: Firstly, we want to contribute to a better understanding of the patterns of innovation in the service sector which covers a broad range of activities with very different kinds of innovations. Secondly, we shall explore the relative merits of the classification and the ranking approach as a means to analyse the innovation process; in this way, we hope to define the range of application of the two ways of looking at the matter.

The set-up of the paper is as follows: The procedure and the variables we use in searching for innovation modes as well as the variables to characterise such patterns are described in the next section. Section 3 gives some information on the data we used in this exercise. The empirical results of the search for innovation modes and their main characteristics are presented in section 4 . In section 5 we are looking at the relationship between the innovation modes we identified and a) their structure by industry and $b$ ) the (average) economic performance of the clusters' firms. Based on these results we shall assess the relative merits of the classification and the ranking procedure. Finally, we summarize and discuss the main results and draw some conclusions.

\section{Procedure}

In contrasts to Evangelista (2000) who uses industry data the present analysis is looking for innovation modes based on firm-level information. In a first step of analysis we try to group firms into homogeneous categories, which can be interpreted as innovation modes, by use of cluster analysis. In order to group the firms we take consideration of their characteristics with respect to a large number of innovation indicators. Cluster analysis, however, is not directly applied to these variables. We started by synthesising (and standardising) the information contained in these measures by means of a (principal component) factor analysis into a small number of variables (,,principal components“). ${ }^{5}$ The latter are used then in a (non-hierarchical) cluster analysis in order to group the firms into a number of categories which are with respect to the variables under investigation as homogenous as possible (small within-cluster variance) and at the same time as different as possible from each other (large between-cluster variance). ${ }^{6}$ In a second step the clusters identified are interpreted in terms of

4 To mention is also an explorative taxonomy of service industries proposed by Antonelli et al. (2000) which is based on other criteria than those used in Evangelista (2000) and the present paper.

5 This procedure produces linear combinations of the original variables (principal components). The latter are standardised variables which are not correlated and contain the common information of the underlying variables. The choice of the number of principal components depends on statistical criteria as well as the plausibility and interpretability of the resulting factor pattern in economic terms; see Manly (1986) for an introductory treatment of principal component factor analysis.

6 This procedure involves partitioning of the sample with observations being allowed to move in and out of groups at different stages of the analysis. At the beginning some more or less arbitrary group centres (,cluster seeds“) are chosen and individual observations allocated to the nearest one. An observation is then moved to another group if it is closer to that group's centre than to the centre of the initial group. This process during which close groups are merged and distant ones split is continued until stability is achieved with a predetermined number of clusters (see Manly, 1986). 
the innovation indicators used in the cluster analysis itself and - more importantly - a large number of additional variables which cover the firms' position in knowledge networks, the environment with respect to a couple of supply- and demand-side determinants of innovative activity, some structural firm characteristics such as size, age, industry, etc. and the firms ${ }^{\star}$ economic performance.

The identification of the clusters (innovation modes) is based on the information contained in the seventeen innovation indicators listed in table 1. These measures cover all stages of the innovation process, i.e. the input and the output side of the generation of innovations as well as the degree of novelty of newly introduced products and the cost element of new processes. On the input side, in addition to the classical aspects of research and development which for several service industries are of minor importance, we take account of the expenditures for IT (hardware as well as software) and the level and composition of innovation-related follow-up investments (innovative machinery, acquisition of external knowledge such as licences, trademarks, etc., human capital investments, marketing outlays). The output side of innovative activity is captured, firstly, by the firms' assessments with respect to the technical as well as the economic significance of the innovations; in addition, we include a variable measuring the IT content of innovation output again evaluated by the firms themselves; moreover, we use two indicators representing a firm's innovation output in terms of patent applications and licences granted. At last, the sales share of innovative products and cost reductions induced by process innovations, both representing innovation-related improvements of the firms" market position, are used as market-oriented innovation indicators. The measurement scales and the corresponding value ranges of these variables are also shown in table 1 . Most of them are qualitative in nature, i.e. either binary (yes/no) or ordinal with five response levels ranging from ,very low“ (value 1) to ,very high“ (value 5). The information content of such subjective measures is high as has been shown in some earlier econometric work devoted to the explanation of the innovativeness of firms measured alternatively by quantitative and qualitative indicators of R\&D inputs (Arvanitis and Hollenstein, 1996).

\section{Table 1}

Step 2 of the analysis is devoted to the description and interpretation of the clusters identified in step 1. To this end we used the variables listed in table 2 :

- A first group of indicators contains the innovation measures used in clustering and some additional indicators characterising a firm's innovative activities. The latter set is made up, firstly, by quantitative measures of $R \& D$ and innovation expenditures as well as of cost reductions directly linked to process innovations. These variables were already included as qualitative measures in the clustering procedure. In addition, we take account of the relative importance of product and process innovations as well as combinations of the two which in most instances indicate more complex innovations. The „degree of novelty“ pertains to information indicating whether the innovation is „new for the industry“ or just „new for the firm“ (reflecting rather adoption than innovation) or whether it is an improvement of an already existing product/service (incremental innovation). 
- A second group of variables deals with the knowledge network which the firms belong to. Under this heading we take account of the intensity of use of fourteen external knowledge sources: clients/customers, three categories of suppliers (material/components, equipment, software), competitors/firms of the same industry, firms of the same enterprise group, universities, other research institutions, consulting firms, technology transfer institutions, patent disclosures, professional conferences/journals, fairs/exhibitions and computer-based networks. Moreover, we include variables representing $\mathrm{R} \& \mathrm{D}$ out-contracting as well as institutionalised $\mathrm{R} \& \mathrm{D}$ cooperations; for both types of arrangements it is distinguished between domestic and foreign relationships with different types of partners. There are good reasons to draw on such detailed information with respect to the use of external knowledge. First, the importance of co-operation and networking for the generation of innovations has grown significantly over time (Haagedoorn, 1996, for Switzerland see Arvanitis et al., 1998); secondly, the structure of use of external knowledge is one of the most important features of the patterns of innovations identified in the studies mentioned in section 1 dealing with the manufacturing sector.

- A third group of variables used in characterising innovation modes represents the main factors determining innovative activity as identified in earlier work related to Swiss manufacturing (Arvanitis and Hollenstein, 1994 and 1996) and services (Arvanitis, 2000). ${ }^{7}$ On the demand side we take account of the medium-run demand perspectives as well as the intensity of price and nonprice competition on the relevant product markets. On the supply side, we include a variable representing a firm's assessment of the (overall) potential for generating novelties in or around the fields of its activities as a proxy for innovation opportunities and a measure for the appropriability of knowledge which is important as an incentive to exploit these innovation potentials. Human capital is added to this third group of variables because firms well-endowed with highly skilled personnel (in addition to be engaged in R\&D) are in a good position to absorb knowledge from other sources (Cohen and Levinthal, 1989).

- The fourth group of variables refers to some structural characteristics of a firm such as industry, size, age and export orientation.

- At last, the description of clusters pertains to firm performance measured by value added per employee as well as the change of sales ${ }^{8}$ and employment over time.

\section{Table 2}

To evaluate the relative merits of ranking and classification we investigate the relationship between innovation modes and their structure by industry. If the clusters are composed of several industries, i.e. if they are not concentrated on a few industries, or - a less restrictive condition - if the industry composition of the clusters is similar to that of the service sector as a whole, the heterogeneity hypothesis is confirmed; in this case classification is a more sensible procedure than ranking. The same holds if the (average) economic performance of the firms of the various innovation modes does not significantly differ from each other.

7 See Cohen (1995) for a detailed survey of the empirical literature dealing with the explanation of innovative activities.

8 We do not dispose of information with respect to the change of value added. 


\section{Data}

The data used in this study are from the Swiss Innovation Survey 1999 which in its core questions is comparable to the „Community Innovation Survey“ (CIS II) conducted in most European countries. The survey was based on a (disproportionally) stratified random sample (28 industries and - within each industry - three firm size classes based on industry-specific employment thresholds with full coverage of the class of large firms). The firms were asked to fill in a questionnaire ${ }^{9}$ about their $^{2}$ innovative activities and a large set of other variables relevant to the description of the innovation process and the explanation of innovative activity and economic performance during the period $1997 / 99$.

The present analysis is confined to the sub-sample of services (2731 firms; nine industries). We received valid answers from 880 firms, i.e. $32.2 \%$ of the underlying sample. The response rates are not too different across industries and size classes with a few exceptions as can be seen from table A1 in the appendix. Nevertheless, in view of the rather low (overall) response rate it was necessary to conduct a survey among a sample of non-respondents using a few core questions related to innovative activity (response rate 90\%). The non-response analysis did not indicate a serious selectivity bias with respect to the structure of the basic sample. By imputing missing values in case of item nonresponse ${ }^{10}$ we could avoid a loss of observations which might have led to a biased sample. In sum, the data set may be considered as representative for the underlying sample. For obvious reasons the search for innovation modes is based on the sub-sample of innovative firms only, that is $54 \%$ of the respondents; see table A1, which shows also the share of innovating firms by industry and firm size classes.

\section{Innovation Modes: Identification and Characteristics}

\subsection{Identification}

As mentioned in section 3, to identify innovation modes, firstly, we used principal component factor analysis to standardise the underlying variables and to synthesise their information content in a number of uncorrelated variables (i.e. „principal components“ or „factors“); secondly, a cluster analysis served to group the firms into a predetermined number of clusters which, if the procedure yields satisfactory results, may be interpreted as innovation modes.

The preliminary step of factor analysis, whose results are shown in detail in table A2 of the appendix, yielded statistically satisfactory results. The five factors extracted in the analysis account for $56 \%$ of total variance. The factor solution is convincing in economic terms as can be seen from the factor pattern depicted in table A2. The first factor accounting for $20 \%$ of total variance gives high weights to innovation-related follow-up investments (level and various components such as training, marketing-related outlays, etc.). The second factor capturing $11 \%$ of the variance shows high loadings on R\&D input and science-oriented innovation output (patent applications, licences granted). The

9 There is a German, a French and an Italian version of the questionnaire which can be downloaded from www.kof.ethz.ch.

10 The method we used is „multiple imputation“ (Donzé, 2000) which has been mainly developed by Rubin (1987). 
third factor explaining $10 \%$ of total variance refers to the technological and IT dimension of service innovations. Whereas the first three factors do not differentiate between product and process innovations the last two components do with both stressing the economic side of innovation: The fourth one loads heavily on product market-orientation, the last one on cost reductions related to process innovations.

Then we performed a non-hierarchical cluster analysis of the five principal components identified in the first step. According to the usual statistical criteria (approximate expected overall $\mathrm{R}^{2}$, cubic clustering criterion, etc.) groupings with four, five or six clusters were more or less of equal quality. In order to choose the number of clusters we took account of three criteria, that is a) the statistical properties in terms of the relationship of within-cluster as compared to between-cluster variance, b) the plausibility of the clusters in economic terms (,can the clusters convincingly be interpreted as innovation modes“?), and c) a cluster must contain a minimum number of firms. According to the last criterion the version with six clusters was not attractive, whereas the solution with four clusters was inferior to that with five groups in terms of criteria a) and b). We thus ended up with a five cluster solution which is satisfactory in statistical terms (the approximate expected overall $\mathrm{R}^{2}$ of 0.45 points to an acceptable fit of the data to the underlying clustering model) and yields a set of innovation modes which have a straightforward interpretation. ${ }^{11}$

\subsection{The basic characteristics of the five innovation modes}

The five innovation modes we identified are described in detail in the appendix (see table A3) based on the variables listed in table 2 . In the following we characterise the five categories in a summary way.

\section{Mode 1: „Science-based fully network-integrated high-tech firms“}

This cluster consists of 21 firms which are endowed with an excellently qualified staff doing very much R\&D within a highly favourable environment in terms of technological opportunities and market perspectives. Own R\&D is supported by intensive use of science-related external knowledge sources as well as many institutionalised R\&D co-operations (and research contracts) with domestic and foreign universities as main partners. The innovation output consists in many instances of products/processes which are new for the industry and are protected by patents (accompanied by granting of licences). The sales share of new products is high, partly due to a significant number of young firms. This cluster contains an above average share of export-oriented medium-sized and some very large firms heavily concentrated in IT/R\&D-services, business services (together 70\% of firms) as well as banking/insurance/other financial services (15\%). Labour productivity is distinctly belowaverage; however, growth performance is more favourable, about average in terms of sales and very strong with respect to employment.

11 As stressed in the literature there is no such thing as a „,natural“ or „correct“ classification; statistical criteria are primarily helpful to narrow down the range of possible solutions within which a satisfactory one has to be identified. 


\section{Mode 2: „IT-oriented network-integrated developers“}

This cluster contains 19 firms which dispose of good preconditions for innovative activities in view of very favourable market perspectives and a highly qualified labour force. Based on high investments in development and IT (but not in research) the firms of this cluster generate product and process innovation which are of high technical standard and, in many instances, new to the industry. The innovations, often patented and licensed to other firms, are technology-oriented and characterised by a high IT-content and a strong potential for cost reductions. These firms are intensive users of manifold sources of external knowledge (suppliers of software and investment goods, universities, competitors and other firms of the same enterprise group). Among the more formal knowledge links outcontracting of R\&D (at home as well as abroad) and the use of licenses are of higher importance than more far-reaching R\&D co-operations. Medium-sized and export-oriented firms are distinctly more frequent in this cluster than in services as a whole. Compared to the sector average IT/R\&D-services as well as banking/insurance/other financial services are represented more than proportionally, whereas the opposite is true for retail trade, hotels/restaurants and real estate which are characterised on average by a rather low innovation intensity. Value added per employee is on average distinctly higher than in the other four categories of firms; growth of sales and employment, however, is lower than in services as a whole.

\section{Mode 3: „Market-oriented incremental innovators with loose external links“}

Innovative activities of the 99 firms belonging to this cluster profit from very favourable market perspectives whereas the supply-side conditions for the generation of novelties are just average. The firms of this cluster generate product and process innovations with a high IT-content which are primarily incremental in nature (which is no surprise in view of the rather low innovation input). Nevertheless innovation output is of high value in economic and technological terms and is successfully brought to the market place. In general, networking is rather weak; only market-oriented knowledge sources (users, software suppliers) and easily accessible knowledge sources (fairs/exhibitions, computer-based networks) are of some importance. Compared to the sector average this cluster is made-up of a high proportion of (very) small firms with average export orientation. The firms are distributed across industries quite similar as services as a whole with some overrepresentation of business services and wholesale trade and only few firms in transport/telecommunication. Labour productivity of this innovation mode is high, whereas growth of sales is not more than average with even weaker employment growth.

\section{Mode 4: „Cost-oriented process innovators with strong external links along the value chain“}

This cluster with 229 firms is by far the largest one. In view of strong price competition and only slightly above-average market growth it is no surprise that (incremental) cost-reducing process innovations are the most prominent feature of innovative activity. Innovation input concentrates on IT-expenditures and innovation-related follow-up investments with all components highly relevant (machinery, external knowledge, training, marketing). The technological and economic significance of innovation output is high although, as mentioned, it is frequently based on further developments of already existing processes. The firms' own innovative activity strongly benefits from a wide 
(primarily informal) network which is spanned along the value chain: from suppliers (of software in particular) at the one end to users at the other, with strong links to different partners in-between (consulting firms, competitors/firms of the same industry, fairs/exhibitions, computer-based networks, professional conferences). Institutionalised co-operation ( $R \& D$ contracts, $R \& D$ co-operation) is only of average importance. Large firms are somewhat over-represented, very small ones distinctly underrepresented in this cluster, and export orientation is rather low. In view of the large number of firms of this cluster it is not surprising that the industry structure is close to the sector average. The same holds for labour productivity; the growth of sales, however, is higher than in any other cluster and employment growth is also above-average.

\section{Mode 5: „Low-profile innovators without external links“}

The (process) innovations of the 107 firms belonging to this cluster seem to be quite marginal what is no surprise in view of the unfavourable demand- and supply-side factors determining innovative activity: weak demand perspectives, strong price competition, low appropriability and innovation opportunities and relatively poor human capital endowment. This cluster shows the weakest performance with respect to most of the variables we use to characterise the various innovation modes. The adoption of novelties generated elsewhere is the most important form of innovation. Correspondingly, innovation input is mainly restricted to buying machinery/equipment. The use of external knowledge, which is distinctly below average for almost all sources, is concentrated on suppliers and competitors. This cluster comprises a more than proportional share of small firms, most of them producing for domestic markets, and of firms belonging to industries like personal services, real estate, hotels/restaurants, retail trade and transport whose innovation intensity is low or only moderate. Not surprisingly, the (average) economic performance (level, growth) of the firms belonging to this cluster is low.

It follows from this characterisation that the five clusters clearly differ from each other in terms of a number of characteristics of high relevance for innovative activity. This holds not only for the description in terms of the seventeen innovation indicators underlying the cluster analysis (table 1) but also - and most importantly - in terms of the large number of „external criteria“ which are not used in the clustering process (see table 2). In view of these consistent and economically plausible patterns the five clusters can be safely interpreted as specific modes of innovation.

\section{Are Innovation Modes Equivalent in Economic Terms?}

It is general practice to rank industries according to their innovativeness with the objective, for example, to assess their competitiveness or to predict their opportunities and risks in structural change (e.g., European Commission, 1997). As mentioned in section 1 ranking is sensible if industries are sufficiently homogeneous with respect to innovation intensity. This assumption holds only if innovation modes, which are homogeneous groups by construction, and industries closely correspond. In addition, to make inference from innovation rankings by industry to competitiveness (and the like) requires - as a necessary though not sufficient condition - systematic differences between innovation modes in terms of economic performance. It is precisely this hypothesis which is denied by advocates 
of the classificatory approach to innovation. In the following we shall discuss the first of these conditions, whereas section 5.2 will be devoted to the second one.

\subsection{Relationship between innovation modes and industries}

Table 3 shows the industry composition of the five innovation modes and the service sector as a whole. Industries are ordered by decreasing innovation intensity the latter being measured by an indicator which aggregates the information contained in the seventeen innovation measures listed in table 1 by means of a factor analysis (for this procedure see Hollenstein (1996)). Although the five innovation modes are primarily regarded as unordered classes, they could also be ranked - at least by tendency - according to innovation intensity with mode 1 (,science-based fully network-integrated high-tech firms“) at the top and mode 5 (,low-profile innovators without external network“) at the bottom of the ladder.

A first look at table 3 shows that the firms of four out of five innovation modes (exception: mode 1) are distributed to many industries, a fact which contradicts the „homogeneity assumption“. However, at least three innovation modes are quite strongly concentrated on few industries. This holds most clearly for mode 1 (,science-based fully network-integrated high-tech firms“) containing mainly firms from the two most innovative industries. The industry composition of mode 2 (,IT-oriented networkintegrated developers") - though somewhat less pronounced - is also biased towards the most innovative industries. Just the opposite is true for mode 5 (,low-profile innovators without external network") which, in comparison with the sector average, is mainly present in industries with low or intermediate innovation intensity. Less pronounced is the concentration of mode 3 (,,market-oriented incremental innovators with loose external links“), whereas firms of mode 4 (,cost-oriented process innovators with strong external links along the value chain") are distributed across industries almost in the same way as the service sector as a whole (what is not very surprising, however, in view of the fact that more than half of the firms of our sample belongs to this group).

We find thus, on the one hand, a clear correspondence between industries (if ranked by innovation intensity) and innovation modes (as supported by a statistically significant value of Goodman-Kruskal $\gamma$ which is an appropriate measure of association in case of ordinally-scaled variables); on the other hand, four out of five innovation modes are distributed quite widely across industries. In sum, the evidence does not clearly favour one of the competing hypothesis (classification vs. ranking).

\section{Table 3}

\subsection{Innovation modes and economic performance}

To assess the validity of the „homogeneity hypothesis“ we have also to investigate whether there are significant differences between the innovation modes with respect to average firm performance. A negative result would support the ,heterogeneity hypothesis“ according to which there is - at least temporarily - more than one economically feasible innovation strategy. To evaluate the two conflicting propositions we consider labour productivity (value added per employee (full-time equivalents)) 
as a measure of firm performance and sales and employment growth as indicators of the development of performance over time.

As can be seen from table 4 labour productivity differs strongly between the five innovation modes; it is $44 \%$ higher in mode 2 (cluster with the highest productivity) than in mode 1 (cluster with the lowest productivity). We find also pronounced differences with respect to the growth of sales and employment respectively. These data seem to be at variance with the „heterogeneity hypothesis“. However, this view of the matter is too simple because firm performance is determined not only by the variable „innovation mode“ but also by other factors such as those listed in the lower part of table 4. For example, it is obvious that a firm which uses intensively physical capital exhibits higher labour productivity than one producing in a more labour-intensive way. This example is clearly relevant in comparing average labour productivity of innovation mode 3 (high value added, high capital intensity) with that of mode 1 (low value added, low capital intensity).

\section{Table 4}

To control for such differences with respect to the use of various input factors we performed a crosssection regression analysis of firm performance in a production-theoretic setting. More specifically, we estimated a production function with the following arguments: a) physical, human and knowledge capital respectively measured by gross capital income per employee, the employment share of personnel holding tertiary level degrees and the share of firms with R\&D activities (or the share of R\&D personnel in total employment); b) dummy variables for the innovation modes (cluster 1 as reference group); c) industry dummies (as variables to control for unspecified factors; personal services as reference group). In explaining sales and employment growth we used the same variables complemented by two dummies to control for changes of the firms' ${ }^{6}$ structure (selling-off, splitting or closure of parts of the firm and mergers respectively). Sales growth and the average wage level have been used as additional variables in explaining employment change. Growth of sales and employment have been measured on an ordinal scale (alternatively with 2, 3 or 6 categories) or as a percentage change.

The estimation results may be summarised as follows:

- Labour productivity: We find a statistically significant impact (positive sign) on firm performance only in the case of innovation mode 2 („IT-oriented network-integrated developers“). The other four modes are thus equivalent in terms of labour productivity. The differences with respect to value added per employee as shown in table 4 are explained primarily by physical as well as human and/or knowledge capital intensity (positive signs). In addition, we obtain statistically significant signs for some industry dummies which are negative in case of two less innovative industries (retail trade, hotel/restaurants) and positive for the highly innovative banking/insurance industry.

- Sales growth: Two of the dummies measuring a firm's innovation mode exert a statistically significant influence on sales growth, innovation mode 2 („IT-oriented network-integrated 
developers") a negative one, mode 4 (,,cost-oriented process innovators with strong external links along the value chain") a positive one. We find a positive, though not in all specifications statistically significant influence of knowledge capital intensity, whereas human and physical capital variables yielded no significant results. The two dummies controlling for changes over time of the firms' boundaries showed the expected sign and were statistically significant. In addition, two industry dummies (wholesale trade, banking/insurance) have a significant positive impact.

- Employment growth: The effects of particular interest are again those referring to the modes of innovation. However, none of the corresponding dummy variables is statistically significant. The most important variable in explaining employment change is, not surprisingly, the growth of sales. Moreover, the wage level exerts the expected negative influence on employment growth. The two variables controlling for changes of the firms' structure show the right signs and were statistically significant. A positive impact is found for the industry dummy IT/R\&D-services. The intensity of use of the various input factors is important (human capital in particular), but these effects are not very stable across different specifications of the variable „employment growth“.

In sum, the estimates of the relationship between firm performance and innovation mode (with mode 1 as reference) lead to the conclusion that - with one exception (mode 2) - a firm's labour productivity is independent of its innovation mode. The same holds (without exception) for the growth of employment, whereas for sales growth we get a significant negative impact of innovation mode 2 and a positive one of mode 4 . The differences between the innovation modes with respect to the three performance measures are thus only in (some of) the „extreme cases“ (see table 4) systematic in nature. These results are more or less in concordance with the „heterogeneity hypothesis“ stating that firms dispose of a certain freedom in choosing economically viable innovation strategies. On the other hand, an assessment has to take into account that the intensity of use of human and/or knowledge capital as well as some of the industry dummies systematically related to innovativeness exert a statistically significant influence on productivity. In view of this result we conclude that the choice of an innovation strategy depends also quite strongly on structural characteristics which are closely related to the hierarchy of industries in terms of innovation intensity.

\section{Summary, Discussion, Conclusions}

By applying cluster analysis to a large set of innovation indicators (which capture also non-technical aspects of innovation which are much more important in services than in manufacturing) we identified five clusters. These were characterised by using several groups of variables: a) innovation indicators, b) the firms ' position in knowledge networks (use of external knowledge sources, R\&D out-contracting and co-operative agreements), c) demand- and supply-side determinants of innovative activity (market perspectives, competitive environment, innovation opportunities, appropriability, human capital endowment), d) some general characteristics of firms such as size, export orientation, industry, and e) measures of firm performance. 
The description of the five clusters in terms of these characteristics showed that they can be interpreted as specific ,,modes of innovation“ which have an economically plausible interpretation:

- „Science-based fully network-integrated high-tech firms“

- „IT-oriented network-integrated developers“

- „Market-oriented incremental innovators with loose external links“

- „Cost-oriented process innovators with strong external links along the value chain“

- „Low-profile innovators without external network“

According to the evolutionary view of technical change such a classificatory procedure (,innovation

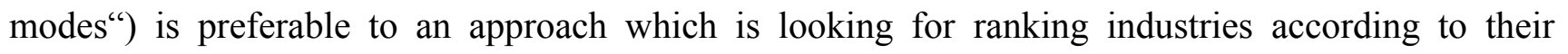
innovativeness. Whereas the starting point of classification is the heterogeneity of firms with respect to innovation strategies, the ranking approach assumes that an industry is rather homogeneous in terms of the innovativeness of its firms. To evaluate the relative merits of the two approaches we investigated in a first step the relationship between innovation modes and industries. We found that the firms of most innovation modes are distributed over several industries; on the other hand, compared to the service sector average, three out of five innovation modes are concentrated on specific industries, and we find a significant positive correspondence between innovation modes and industries ranked according to innovation intensity. In a second step we analysed the relationship between innovation modes and firm performance as well as its change. We found that a firm's labour productivity is independent of its innovation mode (except in one case) with a somewhat stronger relationship between innovation strategies and sales change but no correlation with the growth of employment. On the other hand, there is strong evidence that variables related to innovativeness such as human and knowledge capital intensity as well as dummies for industries with an above-average (below-average) innovation performance exert a positive (negative) influence on firm performance.

In view of the results of both steps of analysis neither the „classical“ ranking of industries according to their innovativeness nor the classification of firms into (unordered) categories representing innovation modes of equal ,economic value“ captures the whole reality. This ambiguous result can be interpreted as follows: On the one hand, in accordance with the heterogeneity hypothesis (classification approach), firms dispose of a certain degree of freedom in selecting an economically viable innovation strategy even in similar economic and technological environments, but the room of manoeuvre is restricted by structural characteristics which are closely related to the hierarchy of industries in terms of innovation intensity (ranking approach). Therefore the „classical“ approach of ranking industries according to their innovativeness, for example, in order to assess their competitiveness, etc. makes still sense. In this framework, however, the measurement of innovation intensity must be broadly based and cover also non-technological indicators; only in this way one can take account of the diversity of innovation modes within an industry (see also Baldwin and Gellatly (1998) for this argument). This aspect rarely gets the attention it deserves; most rankings are based just on a single indicator which is easy to collect, such as R\&D or patent intensity; but these indicators, as shown, are irrelevant for innovative activities of three out of five innovation modes. The aggregate innovation measure we used to rank industries according to their innovation intensity in 
table 3 is a useful instrument to take account of the heterogeneity aspect, because it contains the information of seventeen innovation indicators covering many different aspects of ,innovativeness“ with only some of them technology-oriented.

Are innovation modes similar across countries? This interesting question is difficult to answer at this stage of research. Evangelista (2000), to our knowledge the only study which is more or less comparable to the present one (though based on industry-level data), identified four groups of clusters (derived from a total of nine clusters). Excluding his fourth group which covers just one industry (technical consultancy) we get the following picture: One cluster group found for Italy (,S\&T-based“) is more or less identical to our first innovation mode (,science-based fully network-integrated hightech firms“) and two others (,interactive and IT-based“ and „technology users“ respectively) show some similarities to our clusters 4 and 5 (,,cost-oriented process innovators with strong external links along the value chain“ and „low-profile innovators without external network“ respectively). However, there is no correspondence to our innovation modes 2 and 3. To some extent this result might reflect the specific procedure used in the Italian case where at a certain stage of the analysis the indicators referring to the market-orientation of innovations were dropped for technical reasons (Evangelista, 2000, p. 211). In these circumstances it would have been surprising if a cluster similar to our third one (,market-oriented incremental innovators with loose external links“) had been identified. In sum, there is preliminary evidence for some similarity of innovation modes across countries. This hypothesis should be tested in further work using the same type of data and method of analysis for several countries. In view of the harmonisation of innovation surveys in Europe this research strategy might be feasible. It should thus become possible to identify common as well as country-specific modes of innovation. The latter could be an important element of characterising „National Innovation Systems“...12

At this stage of research one has to be cautious in drawing policy conclusions. Nevertheless the results have some implications to be considered by policy makers. Firstly, in assessing and shaping policy measures one should take account of the variety of innovation patterns identified in this paper because firms belonging to specific innovation modes have different needs with respect to public policy. For example, firms belonging to the innovation mode „IT-oriented network-integrated developers" presumably would profit most from programmes facilitating the diffusion of IT and from measures contributing to enlarge and improve the supply of IT-professionals; on the other hand „science-based fully network-integrated high-tech firms“ may be supported, in the first place, by strengthening the production of (basic) scientific knowledge as well as by measures to improve its transfer to the business sector. Secondly, in view of the poor economic performance of ,low-profile innovators without external network" measures suitable for strengthening outside links could be contribute to improve innovativeness of this type of firms. Thirdly, to the extent that innovation modes are country-specific there are limitations for designing best policy practices at international

12 For manufacturing, there is evidence for such country-specificities (though common patterns dominate) as shown in Arvanitis and Hollenstein (1998): In the Swiss economy, there is no „scale-intensive mode of innovation“ as identified for Britain, Italy and the large European firms, a result which is not surprising in view of the small size of the Swiss economy and its high share of small firms compared to other countries (OECD, 1994). 
level. ${ }^{13}$ Finally, because the overlap between industry structures and innovation modes is only partial and there are only small differences between the various modes with respect to economic performance, it may be advisable to direct policy measures rather towards specific innovation modes than sectors (as „classical“ industrial policy would do) or types of firms (such as, for example, highly $\mathrm{R} \& \mathrm{D}$-intensive ones).

\section{References}

Antonelli, G., Cainelli, G., De Liso, N. and R. Zoboli, 2000, Structural Change and Technological Externalities in the Service Sectors: Some Evidence from Italy, in: S.J. Metcalfe, I. Miles (Editors), Innovation Systems in the Service Sectors, Measurement and Case Study Analysis (Kluwer, BostonDordrecht-London) pp. 187-217.

Arvanitis, S., 2000, Explaining Innovative Activity and its Impact on Firm Performance in Service Industries: Micro Data Evidence for Switzerland, Paper Presented at the „25 $5^{\text {th }}$ CIRET Conference“, Paris, October $10-14$.

Arvanitis, S., Donzé, L., Hollenstein, H. und S. Lenz, 1998, Innovationstätigkeit in der Schweizer Wirtschaft, Teil I: Industrie, Teil II: Bauwirtschaft und Dienstleistungssektor, Studienreihe Strukturberichterstattung, Bundesamt für Wirtschaft und Arbeit, Bern.

Arvanitis, S. and H. Hollenstein, 1994, Demand and Supply Factors in Explaining the Innovative Activity of Swiss Manufacturing Firms, An Analysis Based on Input-, Output- and Market-oriented Innovation Indicators, Economics of Innovation and New Technology 3, 15-30.

Arvanitis, S. and H. Hollenstein, 1996, Industrial Innovation in Switzerland: A Model-based Analysis with Survey Data, in: A. Kleinknecht (Editor), Determinants of Innovation and Diffusion (Macmillan, London) pp. 13-62.

Arvanitis, S. and H. Hollenstein, 1998, Innovative Activity and Firm Characteristics: An Exploration of Clustering at Firm Level in Swiss Manufacturing, Paper Presented at the ,25 $5^{\text {th }}$ Annual Conference of the „European Association for Research in Industrial Economics (EARIE)“, Copenhagen, August 27-30.

Arundel, A., van de Paal, G., and L. Soete, 1995, Innovation Strategies of Europe's Largest Industrial Firms, Report Prepared for the SPRINT Programme, DG XIII of the European Commission.

Baldwin, J.R. and G. Gellatly, 1998, Are There High-Tech Industries or Only High-Tech Firms? Evidence From New Technology-Based Firms, Statistics Canada, Analytical Studies Branch - Research Paper Series, No. 120, Ottawa.

Brouwer, E. and A.H. Kleinknecht, 1996, Determinants of Innovation: A Microeconometric Analysis of Three Alternative Innovation Output Measures, in: A. Kleinknecht (Editor), Determinants of Innovation and Diffusion (Macmillan, London) pp. 99-124.

Cesaratto, S. and S. Mangano, 1993, Technological Profiles and Economic Performance in the Italian Manufacturing Sector, Economics of Innovation and New Technology 2, 237-256.

Cohen, W.M., 1995, Empirical Studies of Innovative Activity, in: P. Stoneman (Editor), Handbook of the Economics of Innovation and Technological Change (Basil Blackwell, Oxford and Cambridge (Mass.)) pp. 182-264.

Cohen, W.M. and D.A. Levinthal, 1989), Innovation and Learning: The two Faces of R\&D, Economic Journal 99, 569-596.

Donzé, L., 2000, Le traitement de la non-réponse partielle dans l'enquête d'innovation 1999, Paper Presented at the ,25 $5^{\text {th }}$ CIRET Conference“, Paris, October 10-14.

Donzé, L. and S. Lenz, 1999, Indicators and Determinants of Innovative Activity in the Service Sector: A First Empirical Analysis with Survey Data, in: K. H. Oppenländer, G. Poser, S. Waller (Editors), Selected Papers Presented at the $23^{\text {rd }}$ CIRET Conference, Helsinki, July 30 - August 2, 1997, CIRET Studien 53, 151-167.

13 See OECD (1998) for an attempt of formulating best policy practices in innovation and technology. 
Ebling, G. and N. Janz, 1999, Export and Innovation Activities in the German Service Sector: Empirical Evidence at the Firm Level, Centre for European Research (ZEW), Discussion Paper No. 99-53, Mannheim.

European Commission, 1997, Second European Report on S\&T Indicators 1997, 2 Vols., Brussels.

Evangelista, R., 2000, Sectoral Patterns of Technological Change in Services, Economics of Innovation and New Technology 9, 183-221.

Gallouj, F. and O. Weinstein, 1997, Innovation in Services, Research Policy 26, 537-556.

Gellatly, G., 1999, Differences in Innovator and Non-innovator Profiles: Small Establishments in Business Services, Statistics Canada, Analytical Studies Branch - Research Paper Series, No. 143, Ottawa.

Haagedoorn, J., 1996, Trends and Patterns in Strategic Technology Partnering Since the Early Seventies, Review of Industrial Organization 11, 601-616.

Hollenstein, H., 1996, A Composite Indicator of a Firm's Innovativeness. An Empirical Analysis Based on Survey Data for Swiss Manufacturing, Research Policy 25, 633-645.

Manly, B.F.J., 1986, Multivariate Statistical Methods. A Primer (Chapman and Hall, London).

Metcalfe, S., 1995, The Economic Foundations of Technology Policy: Equilibrium and Evolutionary Perspectives, in: P. Stoneman (Editor), Handbook of the Economics of Innovation and Technological Change (Basil Blackwell, Oxford and Cambridge (Mass.)) pp. 409-512.

Metcalfe, S.J. and I. Miles (Editors), 2000, Innovation Systems in the Service Sectors. Measurement and Case Study Analysis (Kluwer, Boston-Dordrecht-London).

OECD, 1994, Employment Outlook, Paris, July.

OECD, 1998, Technology, Productivity and Job Creation. Best Policy Practices, Paris.

Pavitt, K., 1984, Sectoral Patterns of Technical Change: Towards a Taxonomy and a Theory, Research Policy $13,343-373$.

Rubin, D.B., 1987, Multiple Imputation for Nonresponse in Surveys (John Wiley \& Sons, New York).

Stoneman, P. (Editor), 1995, Handbook of the Economics of Innovation and Technological Change (Basil Blackwell, Oxford and Cambridge (Mass.)). 


\section{Table 1: Innovation Indicators Used in the Cluster Analysis}

\begin{tabular}{|c|c|c|}
\hline $\begin{array}{l}\text { Innovation } \\
\text { Indicator }\end{array}$ & $\begin{array}{l}\text { Measurement } \\
\text { Scale }\end{array}$ & $\begin{array}{l}\text { Value } \\
\text { Range }\end{array}$ \\
\hline \multicolumn{3}{|l|}{ 1. Input-oriented measures } \\
\hline \multicolumn{3}{|l|}{ Expenditures for } \\
\hline - Research & ordinal & 1,5 \\
\hline - Development & ordinal & 1,5 \\
\hline - IT (hardware, software) & ordinal & 1,5 \\
\hline \multicolumn{3}{|l|}{ Follow-up investments } \\
\hline - Total & ordinal & 1,5 \\
\hline \multicolumn{3}{|l|}{ - By type } \\
\hline - Machinery and equipment & ordinal & 1,5 \\
\hline - Acquisition of external knowledge (licences, trademarks, etc.) & ordinal & 1,5 \\
\hline - Training & ordinal & 1,5 \\
\hline - Market introduction of innovations & ordinal & 1,5 \\
\hline \multicolumn{3}{|l|}{ 2. Output-oriented measures } \\
\hline \multicolumn{3}{|l|}{ - Significance of the innovations in technical terms } \\
\hline - Product & ordinal & 1,5 \\
\hline - Process & ordinal & 1,5 \\
\hline \multicolumn{3}{|l|}{ - Significance of the innovations in economic terms } \\
\hline - Product & ordinal & 1,5 \\
\hline - Process & ordinal & 1,5 \\
\hline - IT-content of innovations & ordinal & 1,5 \\
\hline - Patent application (yes/no) & nominal & 1,0 \\
\hline - Licences granted to other firms (yes/no) & nominal & 1,0 \\
\hline \multicolumn{3}{|l|}{ 3. Market-oriented measures } \\
\hline - Sales share of new or highly improved services (\%) & metric & 0,100 \\
\hline - Cost reduction generated by process innovations (yes/no) & nominal & 1,0 \\
\hline
\end{tabular}




\section{Table 2: Indicators Used to Characterise Innovation Modes}

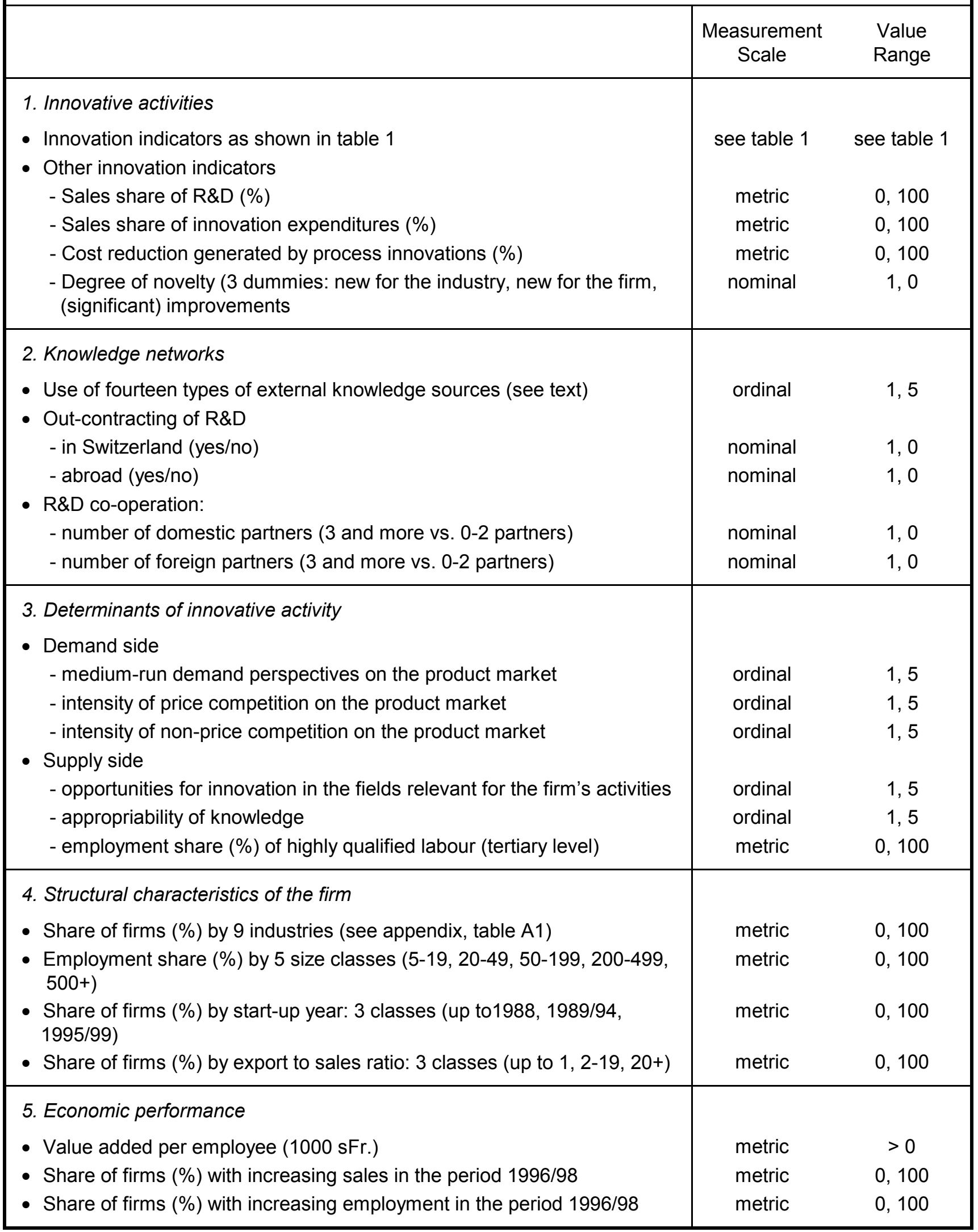

The ordinally scaled variables reflect the firms' assessments on a five-point Likert scale; the response levels range from "very low“ (value 1) to "very high" (value 5). We used the share of firms (\%) with the value 4 or 5 to characterise the clusters in case of ordinal scales; similarly the share of firms $(\%)$ with value 1 (yes) is used in the case of nominal scales. 
Table 3: Industrial Structure by Innovation Mode

\begin{tabular}{|l|r|r|r|r|r|r|}
\hline \multirow{2}{*}{ Industry } & \multicolumn{7}{|c|}{ Innovation Mode } \\
\cline { 2 - 7 } & 1 & 2 & 3 & 4 & 5 & Total \\
\hline Innovativeness above average & \multicolumn{7}{|c|}{ Distribution of firms by industry (\%) } \\
\hline IT and R\&D services & 95.0 & 83.2 & 73.8 & 72.6 & 67.5 & 73.0 \\
(Other) business services & 30.0 & 16.7 & 5.1 & 3.9 & 2.8 & 5.5 \\
Banking/insurance/financial services & 40.0 & 16.7 & 23.2 & 18.3 & 15.7 & 19.6 \\
Wholesale trade & 15.0 & 22.1 & 16.2 & 17.0 & 15.7 & 16.4 \\
Transport/telecommunication & 5.0 & 22.1 & 24.2 & 22.5 & 15.7 & 20.5 \\
\hline Innovativeness below average & 5.0 & 5.6 & 5.1 & 10.9 & 17.6 & 11.0 \\
\hline Retail trade & 5.0 & 16.8 & 26.2 & 27.4 & 32.5 & 27.0 \\
Hotels, restaurants & 0.0 & 5.6 & 14.1 & 13.0 & 16.7 & 13.3 \\
Real estate & 5.0 & 5.6 & 9.1 & 12.2 & 11.1 & 10.7 \\
Personal services & 0.0 & 0.0 & 1.0 & 0.9 & 1.9 & 1.1 \\
\hline Total & 0.0 & 5.6 & 2.0 & 1.3 & 2.8 & 1.9 \\
\hline
\end{tabular}

If in a cluster the industry share of firms (\%) is higher than the share of the industry total in the grand total (column 6 ) by more than $10 \%$ the corresponding cell is shaded. The innovation modes are: (1) „science-based fully network-integrated high-tech firms", (2) „IToriented network-integrated developers“, (3) „market-oriented incremental innovators with loose external links“, (4) „,cost-oriented process innovators with strong external links along the value chain“, (5) „low-profile innovators without external network“; see description in the text and the table $\mathrm{A} 3$ in the appendix. 


\section{Table 4: Economic Performance by Mode of Innovation}

\begin{tabular}{|c|c|c|c|c|c|c|}
\hline \multirow[b]{2}{*}{ Indicator } & \multicolumn{5}{|c|}{ Innovation Mode } & \multirow[b]{2}{*}{ Total } \\
\hline & 1 & 2 & 3 & 4 & 5 & \\
\hline & \multicolumn{5}{|c|}{ Cluster means } & \\
\hline \multicolumn{7}{|l|}{ Performance indicators } \\
\hline Value added per employee (1000 sFr.) & 153 & 221 & 196 & 171 & 172 & 178 \\
\hline Share of firms (\%) with increasing sales 1996/98 & 65 & 39 & 63 & 70 & 57 & 64 \\
\hline Share of firms (\%) with increasing employment 1996/98 & 50 & 28 & 34 & 43 & 32 & 38 \\
\hline \multicolumn{7}{|l|}{ Factors determining firm performance } \\
\hline Gross capital income per employee (1000 Sfr.) & 56 & 67 & 87 & 86 & 72 & 81 \\
\hline Employment share of highly qualified labour (\%) & 50 & 32 & 27 & 22 & 19 & 24 \\
\hline Share of R\&D performing firms (\%) & 100 & 89 & 31 & 45 & 36 & 44 \\
\hline
\end{tabular}

For each indicator the cell with the highest (lowest) cluster mean is shaded in dark (bright) colour respectively. The innovation modes are: (1) "science-based fully network-integrated high-tech firms", (2) „IT-oriented network-integrated developers“, (3) "market-oriented incremental innovators with loose external links“, (4) „cost-oriented process innovators with strong external links along the value chain“, (5) „low-profile innovators without external network“; see description in the text and the table A3 in the appendix. 


\section{Appendix}

\section{Table A1: Structure of the Sample and the Final Data Set}

\begin{tabular}{|l|cc|ccc|ccc|}
\hline & \multicolumn{2}{|c}{ Sample } & \multicolumn{3}{c|}{ Respondents } & \multicolumn{3}{c|}{ Innovators } \\
& $(1)$ & $(2)$ & $(3)$ & $(4)$ & $(5)$ & $(6)$ & $(7)$ & $(8)$ \\
\cline { 2 - 9 } & $\mathrm{N}$ & $\%$ & $\mathrm{~N}$ & $\%$ & $(3) /(1)$ & $\mathrm{N}$ & $\%$ & $(6) /(3)$ \\
\hline Industry & & & & & & & & \\
Wholesale trade & 596 & 21.8 & 207 & 23.5 & 34.7 & 101 & 21.2 & 48.8 \\
Retail trade & 516 & 18.9 & 132 & 15.0 & 25.6 & 63 & 13.3 & 47.7 \\
Hotels, restaurants & 403 & 14.8 & 84 & 9.6 & 20.8 & 50 & 10.6 & 59.5 \\
Transport/communication & 378 & 13.8 & 133 & 15.1 & 35.2 & 52 & 11.0 & 39.1 \\
Banking/insurance & 266 & 9.7 & 99 & 11.2 & 37.2 & 77 & 16.2 & 77.8 \\
Real estate & 38 & 1.4 & 14 & 1.6 & 36.8 & 5 & 1.1 & 35.7 \\
IT and R\&D services & 100 & 3.7 & 36 & 4.1 & 36.0 & 26 & 5.4 & 72.2 \\
Business services & 384 & 14.1 & 155 & 17.6 & 40.4 & 92 & 19.3 & 59.4 \\
Personal services & 50 & 1.8 & 20 & 2.3 & 32.2 & 9 & 1.9 & 45.0 \\
\hline Total & 2731 & 100 & 880 & 100 & 32.2 & 475 & 100 & 54.0 \\
\hline Firm size & & & & & & & & \\
(number of employees) & & & & & & & & \\
Small & 1487 & 54.4 & 465 & 52.8 & 31.3 & 218 & 46.0 & 46.9 \\
Medium & 1021 & 37.4 & 330 & 37.5 & 32.3 & 194 & 40.7 & 58.8 \\
Large & 223 & 8.2 & 85 & 9.7 & 38.1 & 63 & 13.3 & 74.1 \\
\hline Total & 2731 & 100 & 880 & 100 & 32.2 & 475 & 100 & 54.0 \\
\hline
\end{tabular}

Column 5 shows the response rate by industry and size class, column 8 the share of innovating firms. Under-represented industries/size classes are brightly coloured, whereas over-represented ones are darkly shaded; criterion: deviation of more than $15 \%$ of the total. 


\section{Table A2: Factor Analysis with the Innovation Indicators Used in Cluster Analysis}

\begin{tabular}{|c|c|c|c|c|c|}
\hline Innovation indicator & \multicolumn{5}{|c|}{$\begin{array}{l}\text { Rotated Factor Pattern } \\
\text { (Factor loadings) }\end{array}$} \\
\hline & .17 & & & & \\
\hline Follow-up investments: training & .75 & & & & \\
\hline Follow-up investments: machinery and equipment & .67 & & & & \\
\hline Follow-up investments: market introduction of innovations & .66 & & & & \\
\hline Follow-up investments: acquisition of external knowledge & .54 & & & & \\
\hline Development expenditures & & .74 & & & \\
\hline Patent application & & .73 & & & \\
\hline Research expenditures & & .68 & & & \\
\hline Granting of licences & & .61 & & & \\
\hline IT-content of innovations & \multicolumn{5}{|c|}{.80} \\
\hline IT expenditures (hardware, software) & \multicolumn{5}{|c|}{.68} \\
\hline Significance of product innovations in technical terms & \multicolumn{5}{|c|}{.57} \\
\hline Significance of process innovations in technical terms & \multicolumn{5}{|c|}{.57} \\
\hline Sales share of new or highly improved products & \multicolumn{5}{|c|}{.76} \\
\hline Significance of product innovations in economic terms & \multicolumn{5}{|c|}{.73} \\
\hline Cost reduction related to process innovations & & & & & .78 \\
\hline Significance of process innovations in economic terms & & & & & .59 \\
\hline Number of observations & & & & & 475 \\
\hline Kaiser's overall measure of sampling adequacy (MSA) & & & & & .720 \\
\hline Variance accounted for by the first five components & & & & & .557 \\
\hline Root mean square off-diagonal residuals (RMSE) & & & & & .079 \\
\hline Variance accounted for by each factor & 3.32 & 1.94 & 1.68 & 1.46 & 1.06 \\
\hline Final communality estimate (total) & & & & & 9.46 \\
\hline
\end{tabular}

The factor analysis with the innovation variables listed and defined in table 1 led to satisfactory results as can be seen from the factor pattern which seems sensible in economic terms (see upper part of the table) and from the statistical information presented in the lower part: According to Kaiser's MSA the original variables are quite strongly correlated; hence, a basic requirement for a factor analysis to be sensible is fulfilled. Moreover, the RMSE of the residual is low enough, and the variance accounted for by the first five principal components is sufficiently high. Only factor loadings (equamax rotation) above 0.5 are shown. 
Table A3: Description of the Five Innovation Modes Identified for the Service Sector

Mode 1: „Science-based fully network-integrated high-tech firms“

(4.4\% of firms, $18.1 \%$ of employment)

Innovation activities and | Extraordinarily high innovation performance, in particular combined product/innovativeness

process innovations:

Based on very high R\&D expenditures (also at foreign locations) these firms generate basic novelties often protected by patents (with much granting of licences); the innovations, which in many cases are "new for the industry“, are successfully introduced in the market

Knowledge network

Intensive use of (primarily) science-related external knowledge sources (universities, other research centres, patent disclosures, licences, journals); high importance of institutionalised relationships with domestic and foreign partners (R\&D co-operations and contracts) which are very effective in terms of the generation of publications, patents, prototypes and new products

Innovation determinants

- demand side

- supply side

Very good market perspectives in a highly competitive environment

Extremely good innovation opportunities, which - favoured by strong appropriability of knowledge - are realised by an excellently qualified labour force (very high share of academics)

Firm characteristics

- Industry

- Size, age, export orientation

Pronounced concentration on the most innovative industries (IT/R\&D-services, business services)

Besides some very large enterprises, primarily medium-sized firms (with a considerable share of rather young ones) with very strong export orientation

Firm performance

Low labour productivity (combined with very low physical capital intensity); average growth of sales and very strong employment growth

Mode 2: „IT-oriented network-integrated developers“ of firms, $1.7 \%$ of employment)

$(4.0 \%$

Innovation activities and | High innovation performance (products, processes, combined innovations):

innovativeness

Based on high investments in IT and development (but not research) also at foreign locations these firms generate innovations which very often are industry novelties protected by patents and licensed to other firms. The innovations are technology-oriented and characterised by a high IT-content and a strong cost-reducing potential, whereas the sales share of new products is low

Knowledge network

Intensive use of manifold sources of external knowledge (universities, suppliers of software and investment goods, licences, competitors, firms of the same group); institutionalised knowledge relationships (at home and abroad) which take primarily the form of R\&D out-contracting, in second instance also R\&D co-operations (with a high output of patents and new processes)

Innovation determinants

- demand side

Favourable market perspectives with below-average competitive pressure

- supply side

Innovation opportunities are below-average; however, firms can fully use this potential given strong knowledge protection and highly qualified labour

Firm characteristics

- Industry

Some concentration on IT/R\&D-services, banking/insurance/other financial services, whereas retail trade and hotels/restaurants are represented less than in the service sector as a whole

- Size, age, export orientation

Highly export-oriented, primarily medium-sized firms (with a non-negligible share of rather young firms)

Firm performance

Very high labour productivity (combined with low physical capital intensity), but very weak growth of sales and employment 
Table A3 (continued)

\section{Mode 3: „Market-oriented incremental innovators with loose external links“ \\ (20.9\% of firms, $9.1 \%$ of employment)}

Innovation activities and innovativeness

Knowledge network

Innovation determinants

- demand side

- supply side

Firm characteristics

- Industry

- Size, age, export orientation

Firm performance
Average innovation performance for new products as well as processes

These firms generate and introduce successfully innovations which are primarily developments of already existing products/processes. These incremental innovations, which often contain IT-components, are of high value in technological and economic terms, though innovation inputs (R\&D as well as innovation-related follow-up investments) are rather low

These firms are only loosely embedded in knowledge networks. Among the external knowledge sources only some easily accessible ones (fairs, computer-based networks) and some market-oriented sources (suppliers of software, users) are of some importance. The institutionalised knowledge transfer through co-operations and R\&D out-contracting is weak

Bright demand perspectives on markets where competition is not very intensive

Innovation opportunities, appropriability and human capital endowment are about average

The firms are distributed across industries in the same way as the service sector as a whole; there is some overrepresentation of wholesale trade and business services whereas transport/communication is under-represented

High proportion of (very) small firms (some of them rather young) with average export orientation

Labour productivity (and physical capital intensity) are significantly higher than for services as a whole; growth of sales is about average whereas employment growth is weaker than in the service sector as a whole

Mode 4: „Cost-oriented process innovators with strong external links along the value chain“ (48.2\% of firms, $62.9 \%$ of employment)

Innovation activities and $\quad$ High innovation performance concentrated on new processes

innovativeness

These firms generate strongly cost-reducing process innovations, which are primarily developments of existing processes, based on high innovationrelated investments in machinery, training and marketing

Knowledge network

These firms are intensively connected to many types of external knowledge sources which form an (informal) network along the value chain: from suppliers (primarily of software) to users with many partners in-between (consulting firms, competitors, fairs/exhibitions, computer-based networks, professional conferences). The institutionalised knowledge transfer through co-operations and R\&D out-contracting which is of average importance leads primarily to new processes

Innovation determinants

- demand side

- supply side

Firm characteristics

- Industry

- Size, age, export orientation

Firm performance
Slightly above-average demand perspectives combined with strong price competition

Innovation opportunities are slightly higher than for services as a whole; appropriability and skill endowment are somewhat below-average

Industrial structure is almost identical to that of the service sector as a whole

Large firms are somewhat over-represented; export orientation is rather low

Labour productivity is below-average (with very high physical capital intensity); very strong sales growth with above-average employment growth 
Table A3 (continued)

Mode 5: „Low-profile innovators without external network“

(22.5\% of firms, $8.2 \%$ of employment)

Innovation activities and innovativeness

Knowledge network

Innovation determinants

- demand side

- supply side

Firm characteristics

- Industry

- Size, age, export orientation

Firm performance
Very weak innovation performance (primarily process innovations):

The innovations, which in first instance are just „new to the firm“ (adoption), are of quite marginal significance with respect to innovation inputs (buying machinery only). Innovation output in terms of its technological and economic content as well as the impact of innovative activity on sales and costs are low

The use of external knowledge is modest; only suppliers and competitors play a certain role as sources of know-how

Demand perspectives are weak; price competition is intensive and much more relevant than non-price competition

Innovation opportunities, appropriability and human capital endowment are all below average

Industries with (rather) low innovation intensity like real estate, personal services, retail trade and transport/communication are over-represented, whereas firms producing business services and - even more - IT-/R\&Dservices are rare

The share of small firms is high; firms serve primarily domestic markets

Labour productivity is below-average with physical capital intensity also below average); growth of sales and employment are weak 